Proceedings of the International Conference in Dubrovnik, 15-16 October 2015

\title{
EXPERIMENTAL RESEARCH OF PRECAST CONCRETE FLOOR BLOCKS WITH IMPROVED RESISTANCE TO HIGH TEMPERATURE
}

\author{
Dubravka Bjegovića $^{\mathrm{a}}$ Ivana Miličević ${ }^{\mathrm{b}}$, Nina Štirmer ${ }^{\mathrm{a}}$ \\ ${ }^{a}$ Department of Materials, Faculty of Civil Engineering, University of Zagreb, Croatia, Fra Andrije Kačića Miošića 26, \\ 10000 Zagreb \\ ${ }^{\mathrm{b}}$ Department for Materials and Structures, Faculty of Civil Engineering, J. J. Strossmayer University of Osijek, Croatia, \\ Crkvena 21, 31000 Osijek
}

\begin{abstract}
The paper presents possibility of usage of crushed clay bricks and roof tiles as an aggregate for concrete in precast concrete floor blocks. According to literature review, concrete with crushed brick and roof tiles as an aggregate has better thermal properties than regular concrete with natural aggregate. Applicability of concrete mixture for precast concrete blocks was tested regarding the requirements set in HRN EN 15037-2 Precast Concrete products - Beam and block floor systems Part 2: Concrete blocks. Precast concrete blocks with crushed bricks and roof tiles were made and their mechanical properties after exposure to high temperature were tested. Based on experimental results, conclusions are made about usage of crushed bricks and roof tiles as partial replacement of natural aggregate in concrete for precast concrete blocks with improved resistance to high temperatures.
\end{abstract}

Keywords: floor blocks, crushed bricks, concrete, high temperatures.

\section{INTRODUCTION}

Aggregates in concrete comprise up to $75 \%$ of the total volume of concrete, any reduction in natural aggregates consumption will have significant impacts in the environment [1]. The type of recycled material that can be used as an aggregate in concrete is waste from the production of burned clay materials such as brick and tiles. Most of this waste type is already incorporated as raw material for new clay materials, but part of these wastes and those produced by the construction industry are placed in landfills. Debieb and Kenai [2] used coarse and fine crushed bricks and reported a decrease in strength from $20 \%$ to $30 \%$ depending of the degree of substitution. The crushed bricks can be used as natural aggregates substitutes in percentages up to $15 \%$ without strength reduction, Cachim [1]. There are many unsolved problems encountered in controlling the quality of recycled aggregate concrete, which include low compressive strength, wide variability of quality, high drying shrinkage, large creep and low elastic modulus [3-6]. Consequently, most studies recommend a limit of $30 \%$ of recycled aggregate as substitution of natural aggregate. Many researchers have successfully applied recycled aggregate on pavement and roadwork or simple structures, underground structures, foundations, piles and mass concrete. However, use of recycled aggregates in higher grade concrete is not common [3]. According to literature review, concrete with crushed brick and roof tiles as an aggregate has better thermal properties than regular concrete with natural aggregate. Precast concrete blocks with crushed bricks and roof tiles were made and their mechanical properties after exposure to high temperature were tested. Based on experimental results, conclusions are made about usage of crushed bricks and roof tiles as partial replacement of natural aggregate in concrete for precast concrete blocks with improved resistance to high temperatures.

\section{PROPERTIES OF CONCRETE}

Crushed brick, crushed roof tile and dolomite (limestone) have been used as aggregate for concrete mixtures. Crushed bricks and roof tiles were crushed at the factory and delivered to the concrete mixing location. Since both crushed bricks and roof tiles represented a waste product in the process 
of making new bricks and roof tiles, no additional processing of these materials was required as well, because the material was completely pure. Crushed brick and roof tile were manually sifted into $0-4 \mathrm{~mm}, 4-8 \mathrm{~mm}$ and $8-16 \mathrm{~mm}$ fractions. Grading composition of crushed brick and roof tile and dolomite used in further tests is shown in Figures 1, 2 and 3. Portland cement CEM I 42,5 N was used and its characteristic mechanical, physical and chemical properties are set by the manufacturer and are in compliance with norm HRN EN 197-1:2005. When preparing the mixture with addition of superplasticizer, superplasticizer Sika ViscoCrete - 20 Gold was used for high plasticity and early hardness growth. Characteristics of superplasticizer were tested by the manufacturer.

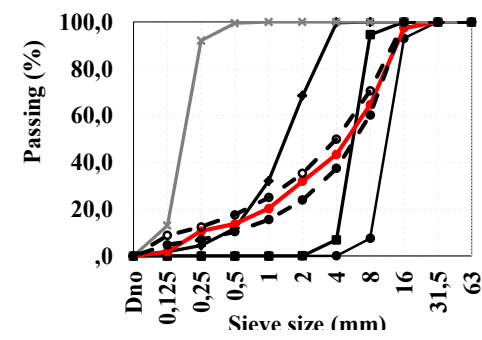

Figure 1 Grading curves for dolomite

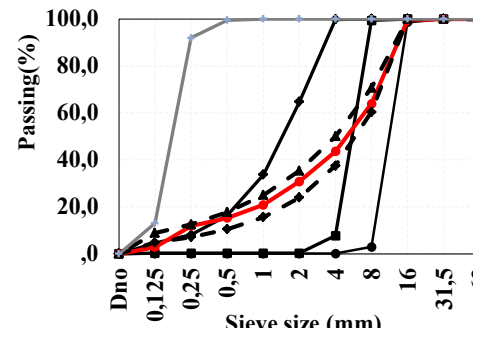

Figure 2 Grading curves of crushed roof tiles

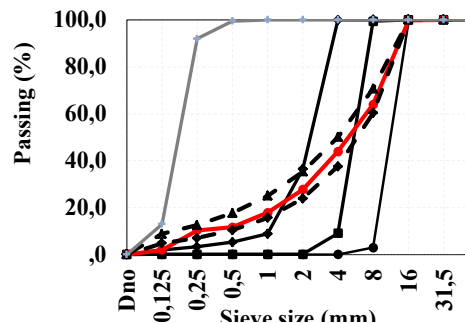

Figure 3 Grading curves of crushed bricks

Selected mixtures' composition is shown in Table 1. When mixing the compound, the aggregate was in saturated, dry-surface state and the total amount of water added to the mixture is shown in Table 1.

Table 1 Concrete composition

\begin{tabular}{|c|c|c|c|c|c|c|c|c|c|c|c|}
\hline \multicolumn{12}{|c|}{ Mix proportions $\left(\mathrm{kg} / \mathrm{m}^{3}\right)$} \\
\hline \multirow[b]{2}{*}{ Mark } & \multirow{2}{*}{ Cement } & \multirow{2}{*}{ Water } & \multirow{2}{*}{$\mathrm{w} / \mathrm{c}$} & \multirow{2}{*}{ Additive } & \multirow{2}{*}{ Filler } & \multicolumn{3}{|c|}{ Fine aggregate } & \multicolumn{3}{|c|}{ Coarse aggregate } \\
\hline & & & & & & (CB) & (CT) & (NA) & (CB) & (CT) & (NA) \\
\hline $\mathrm{RM}$ & 300 & 150 & 0,5 & - & 208,17 & & 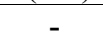 & 608,12 & 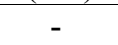 & 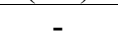 & 1170,97 \\
\hline EM - BM42 & 300 & 150 & 0,5 & - & 208,17 & 113,15 & 118,95 & 304,06 & 205,85 & 438,32 & 292,76 \\
\hline $\mathrm{MM}-\mathrm{B} 10$ & 360 & 165,6 & 0,46 & 1,08 & 197,68 & 214,90 & - & 288,74 & 273,66 & 83,25 & 611,62 \\
\hline
\end{tabular}

After the concrete compositions shown in Table 1 have been mixed, fresh state concrete properties were tested as shown in Table 2. Tests were conducted in accordance with the HRN EN 12350 group of norms for fresh-state concrete.

Table 2 Properties of fresh concrete for mixtures RM, EM-BM42 and MM-B10

\begin{tabular}{|c|c|c|c|c|}
\hline Mark & Density $\left(\mathrm{kg} / \mathrm{m}^{3}\right)$ & Consistency $(\mathrm{mm})$ & Slump & Air content (\%) \\
\hline RM & 2658 & 31,67 & $\mathrm{~S} 1$ & 2,5 \\
\hline EM - BM42 & 2296 & 11,67 & $\mathrm{~S} 1$ & 4,4 \\
\hline MM - B10 & 2353 & 31,67 & $\mathrm{~S} 1$ & 4,2 \\
\hline
\end{tabular}

The Tables 3 and 4 show the results of the hardened concrete properties at 28 and 56 day old at room temperature. The values listed in Tables 3 and 4 infer that the compressive strength of all three concrete mixtures complies with the provisions of norm HRN EN 15037-2:2009 that defines the minimum concrete class $C 12 / 15$ for all weight-carrying floor blocks. It is possible to infer that the compressive strength of the 28-day-old mixture EM-BM42 is 35,2\% lower than that of the RM, as expected. The compressive strength in the 28 -day-old MM-B10 mixture is $18.8 \%$ lower than that of RM. A lesser variation in hardened state of both mixtures MM-B10 and RM, and EM-BM42 and RM likewise, may be the result of lower $\mathrm{v} / \mathrm{c}$ factor $(0,46)$ and the addition of the superplasticizer. Compressive strengths that nearly equal to compressive strength of the common concrete may be achieved in concrete with crushed brick and roof tile as aggregate, taking into account the $45 \%$ limit for coarse and $50 \%$ limit for fine particle fraction in substitution of natural aggregate with crushed brick and roof tile. Flexural strength for mixture EM-BM42 is $17 \%$ of the compressive strength of concrete, for mixture MM-B10 it is $16,6 \%$, and for mixture RM it is $14,5 \%$ of the compressive 
strength of concrete. It may be inferred that the flexural strength of crushed brick and roof tile as aggregate mixture is approximately $7 \%$ to $20 \%$ lower than that of the flexural strength of natural aggregate concrete mixture.

Table 3 Properties of 28-day-old hardened concrete

\begin{tabular}{|c|c|c|c|c|}
\hline Mark & $\begin{array}{c}\text { Compressive strength } \\
\left(\mathrm{N} / \mathrm{mm}^{2}\right)\end{array}$ & $\begin{array}{c}\text { Flexural strength } \\
\left(\mathrm{N} / \mathrm{mm}^{2}\right)\end{array}$ & $\begin{array}{c}\text { Density of hardened } \\
\text { concrete }\left(\mathrm{kg} / \mathrm{m}^{3}\right)\end{array}$ & $\begin{array}{c}\text { Ultrasonic puls } \\
\text { velocity }(\mathrm{km} / \mathrm{s})\end{array}$ \\
\hline RM & 39,36 & 5,71 & 2479,58 & 5,03 \\
\hline EM-BM42 & 25,53 & 4,34 & 2165,27 & 3,89 \\
\hline MM-B10 & 31,95 & 5,31 & 2250,01 & 4,24 \\
\hline
\end{tabular}

Table 4 56-day-old concrete properties in hardened state

\begin{tabular}{|c|c|c|c|c|c|}
\hline Mark & $\begin{array}{c}\text { Compressive } \\
\text { strength }\left(\mathrm{N} / \mathrm{mm}^{2}\right)\end{array}$ & $\begin{array}{c}\text { Flexural strength } \\
\left(\mathrm{N} / \mathrm{mm}^{2}\right)\end{array}$ & $\begin{array}{c}\text { Density of } \\
\text { hardened concrete } \\
\left(\mathrm{kg} / \mathrm{m}^{3}\right)\end{array}$ & $\begin{array}{c}\text { Modulus of } \\
\text { elasticity (MPa) }\end{array}$ & $\begin{array}{c}\text { Ultrasonic puls } \\
\text { velocity }(\mathrm{km} / \mathrm{s})\end{array}$ \\
\hline RM & 45,33 & 6,00 & 2476,05 & 41,85 & 5,07 \\
\hline EM-BM42 & 33,42 & 4,96 & 2100,89 & 19,26 & 3,96 \\
\hline MM-B10 & 37,33 & 5,38 & 2184,44 & 22,60 & 4,13 \\
\hline
\end{tabular}

According to Table 4, the modulus of elasticity of concrete mixtures with crushed brick and roof tile as aggregate is up to $50 \%$ lower than that of concrete with natural aggregate. When designing the resistive or semi resistive construction elements from concrete with crushed brick and roof tile as aggregate in which shrinkage is significant, it is important to take into consideration the lower modulus of elasticity of constructive elements. By comparison of results of the ultrasonic pulse velocity listed in Tables 3 and 4 it is possible to determine how crushed brick and roof tile samples have lower ultrasonic pulse velocity, which may indicate the appearance of defects, cracks, higher porosity and other non-homogeneities. Taking into account the concrete quality classification with regard to ultrasonic speed velocity, it may be concluded that all three mixtures have ultrasonic pulse velocity above $3,60 \mathrm{~km} / \mathrm{s}$, placing them in high quality concrete class, [10]. After laboratory testing of optimum concrete mixtures EM-BM42 and MM-B10 and their comparison to the reference mixture RM, the following can be concluded: EM-BM42 mixture has better physical, mechanical and thermal properties and durability with regard to the application of such concrete in production of precast floor blocks.

\section{PROPERTIES OF CONCRETE FLOOR BLOCKS WITH CRUSHED BRICKS AND ROOF TILES}

The floor block samples were made from concrete the composition of which is given in Table 1 . The concrete blocks with crushed bricks and roof tiles made from concrete mixture EM-BM42 in further text are referred to as BlokOL. After mixing the concrete was cast into moulds of volume and appearance as seen in Figures 5 and 6 . The moulds were made in compliance with the concrete floor block volume regulations prescribed by the norm HRN EN 15037-2:2009. Before the concrete was cast into the moulds, fresh concrete properties were tested for the three samples of each mixture in order to prove and confirm the repetition of experiment. After the concrete was cast, the moulds were covered with nylon foil and left for 24 hours at room temperature of $20^{\circ} \mathrm{C} \pm 5^{\circ} \mathrm{C}$.

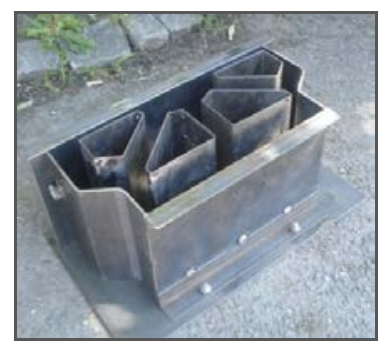

Figure 5 Moulds for concrete blocks

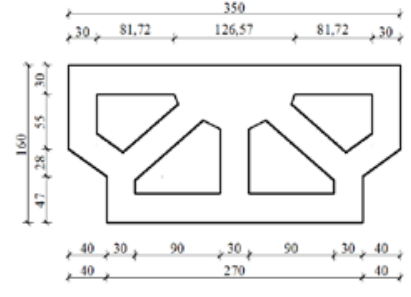

Figure 6 Dimensions of blocks 
The requirements that the BlokOL must fulfil refer to: geometric properties, surface appearance, mechanical resistance, fire resistance, acoustic properties, thermal properties and durability. After 28 days the properties of blocks were tested at room temperature. The testing was conducted on three BlokOL samples and before each test the geometric properties were observed. The surface of the concrete block was controlled visually. The blocks displaying surface errors which could possible affect the mechanical properties were discarded. BlokOL weight was determined after the blocks were dried in the laboratory drying oven at $105^{\circ} \mathrm{C}$ until reaching permanent weight and the volume was determined by measuring dimensions with a slide-ruler. The measured gross dry density in dry state was $1995 \mathrm{~kg} / \mathrm{m}^{3}$. Mechanical properties of the block were tested according to norm HRN EN 15037- 2:2009: Precast Concrete Floor Systems Requirements: Concrete Blocks. The results of the conducted tests are given in Table 5. The tests were conducted on three samples for each tested property and on samples at least 24 hours old in laboratory environment at $20{ }^{\circ} \mathrm{C} \pm 5$ ${ }^{\circ} \mathrm{C}$.

Table 5 Results of testing for mechanical properties of blocks

\begin{tabular}{|c|c|c|c|}
\hline Test & BlokOL & Type of block & Class of mechanical resistance \\
\hline The resistance to concentrated loads $(\mathrm{kN})$ & 6,9 & & $\mathrm{R} 1$ \\
\cline { 1 - 1 } $\begin{array}{c}\text { The characteristic longitudinal compressive } \\
\text { strength }(\mathrm{MPa})\end{array}$ & 18,0 & $\begin{array}{c}\text { Resisting/semi- } \\
\text { resisting }\end{array}$ & $\mathrm{R} 2$ \\
The bending strength $(\mathrm{kN})$ & 13,3 & $\mathrm{R} 2$ \\
\hline
\end{tabular}

Table 5 indicates that BlokOL complies with all the requirements of R2 mechanical resistance classes according to norm HRN EN 15037-2:2009 and that it can be used as a resisting and semiresisting floor block of the precast floor construction. On $28^{\text {th }}$ day the blocks were taken out of the water and left to dry at room temperature for 7 days, after which they were dried in the laboratory drying oven at $105^{\circ} \mathrm{C}$ to permanent mass state, i.e. block humidity lower than $1 \%$. After the desired sample humidity was achieved, the blocks exposed to high temperatures of $200^{\circ} \mathrm{C}, 600^{\circ} \mathrm{C}$ and $800^{\circ} \mathrm{C}$. The temperature growth was $1{ }^{\circ} \mathrm{C} / \mathrm{min}$, and it was measured by a thermal probe located on the very furnace and a control probe placed in the furnace. Block weight was measured before and after the blocks were heated. After exposing the samples to temperature of $600^{\circ} \mathrm{C}$ the sample mass slightly decreases when compared to the ones exposed to $200^{\circ} \mathrm{C}$, i.e. residual mass is about $96 \%$ of the initial weight. After heating the samples at $800^{\circ} \mathrm{C}$, the residual sample weight were around $90 \%$ of the initial mass. The dimensions of a block change due to temperature change. After exposure to $200^{\circ} \mathrm{C}$, a negligible volume increase up to $1 \%$ can be measured. After exposure to temperature over $600^{\circ} \mathrm{C}$, the block volume increases up to $2 \%$ and after exposure to $800^{\circ} \mathrm{C}$ it increases around $5 \%$. Should the length of blocks change in case of a fire, it is necessary to ensure an adequate amount of space catering to that change. Taking into account the listed increases after exposure of BlokOL to temperatures of $600^{\circ} \mathrm{C}$ and $800^{\circ} \mathrm{C}$, and applying it to the dimensions of a block, it is recommended to prescribe a length tolerance of BlokOL leaning at $49 \pm 3 \mathrm{~mm}$. The surface of the concrete block is controlled visually after its exposure to high temperatures. The Figures $7 \mathrm{a}$ ) to $7 \mathrm{~d}$ ) give details of blocks after their exposure to high temperatures, wherein the fractures are painted black to make them more visible in figures since they are fairly difficult to see and minute in reality. From pictures 7a) to 7d) it is visible that the fractures appear on edges of the upper and lower surface of a block, as well as on the edges of block cavities. On blocks exposed to the temperature of $600^{\circ} \mathrm{C}$, tiny fractures were observable, as ex pected in lieu with the results of the earlier material level tests. Likewise, fractures identical to those visible on concrete samples, are observable on the upper, lower and side surface of a block. After exposure to temperature of $800^{\circ} \mathrm{C}$ fractures begin to appear on the outer surface of a block, as well as the edges of BlokOL walls. Presumably, a higher number of tiny web-like fractures on concrete matrix appear due to the difference in concrete BlokOL wall thickness when compared to the EM-BM42 sample prisms. The temperature of the block walls, they being $3 \mathrm{~cm}$ thick, rises significantly faster than the 10 -centimetre thick prism samples when exposed to the same temperature. The overall conclusion is that the geometric properties and faster 
sample core temperature growth are the cause of fractures appearing on the edges of BlokOL, Figure 7.

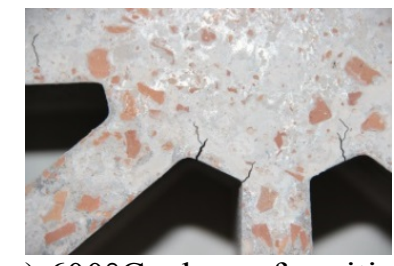

a) $600^{\circ} \mathrm{C}$ edges of cavities

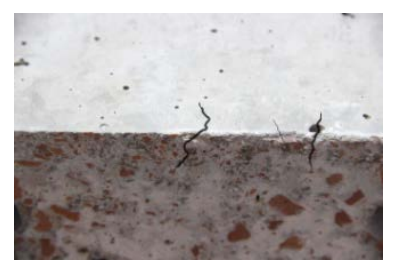

b) $600^{\circ} \mathrm{C}$ upper edge

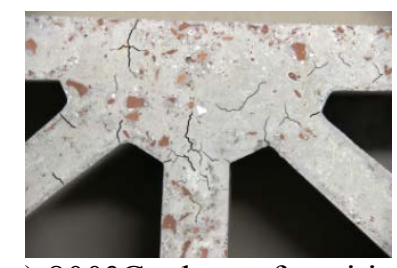

c) $800^{\circ} \mathrm{C}$ edges of cavities

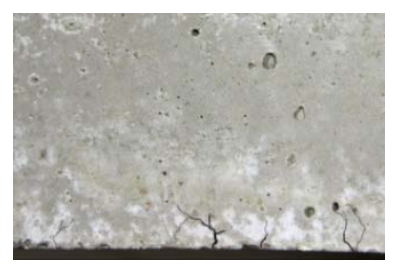

d) $800^{\circ} \mathrm{C}$ upper edge

Figure 7 Details of fractures on the edges of BlokOL after exposure to high temperatures

Mechanical resistance of BlokOL was tested on samples after their exposure to high temperatures and the test results are given in Table 6. The test results indicate that BlokOL possesses a satisfactory mechanical resistance even after its exposure to temperature of $200^{\circ} \mathrm{C}$. Since all mechanical properties, apart from longitudinal compressive strength, are three times higher than prescribed for semi-resisting and resisting blocks, it may be expected that even after their decrease due to high temperature exposure, they will still comply with the regulatory criteria. In accordance with that, after the exposure to temperature of $600^{\circ} \mathrm{C}$ and $800^{\circ} \mathrm{C}$, all properties apart from longitudinal compressive strength still comply with the regulations on mechanical resistance for blocks at room temperature, Table 6 .

Table 6 Results of testing for mechanical properties of blocks after exposure to high temperatures

\begin{tabular}{|c|c|c|c|}
\hline \multirow{2}{*}{ Temperature } & The resistance to concentrated loads & $\begin{array}{c}\text { The characteristic longitudinal } \\
\text { compressive strength }\end{array}$ & The bending strength \\
\cline { 2 - 4 } & $(\mathrm{kN})$ & $(\mathrm{MPa})$ & $(\mathrm{kN})$ \\
\hline $200^{\circ} \mathrm{C}$ & 6,4 & 17,5 & 12,8 \\
\hline $600^{\circ} \mathrm{C}$ & 5,7 & 14,7 & 10,0 \\
\hline $800^{\circ} \mathrm{C}$ & 3,2 & 7,2 & 4,8 \\
\hline
\end{tabular}

From the above it may be inferred that the longitudinal compressive strength of a block is crucial in determining the remaining carrier capacity after exposure to high temperatures and that it is decisive in subsequent establishing of construction state after exposure to fire. Thermal properties of BlokOL are expressed via thermal conductivity of materials together with the product geometry. Thermal conductivity of materials was determined through testing according to norm HRN EN ISO 8302 in dry state. After permanent weight was achieved, the sample was wrapped in polyethylene foil until the moment of testing in order to prevent the humidity level rise in sample. Thermal conductivity of block, the size of which was $50 \mathrm{~cm}$ x $50 \mathrm{~cm} \times 10 \mathrm{~cm}$, was conducted after drying treatment. The test sample (in further text: block) was made from concrete mixture previously marked EM-BM42 and selected as the best one for production of concrete floor blocks. Thermal conductivity measurement results are given in Table 7 . The data from said Table indicate that the coefficient of thermal conductivity $(\lambda)$ at temperature of $10^{\circ} \mathrm{C}$ is $0,631 \mathrm{~W} /(\mathrm{mK})$, whereas for common concrete $\lambda=1,09 \mathrm{~W} /(\mathrm{mK})$. By comparing the listed values, it may be observed that concrete with crushed bricks and roof tiles has up to $58 \%$ lower coefficient of thermal conductivity than the common concrete, implying the former possesses better thermal properties and improved fire resistance.

Table 7 Coefficient of thermal conductivity for BlokOL in dry state

\begin{tabular}{|c|c|c|c|c|}
\hline \multirow[t]{2}{*}{ Property } & \multirow[b]{2}{*}{ Unit } & \multicolumn{3}{|c|}{ Measuring point } \\
\hline & & 1. & 2. & 3. \\
\hline Density of material & $\left(\mathrm{kg} / \mathrm{m}^{3}\right)$ & & 1910, & \\
\hline Flat mass & $\left(\mathrm{kg} / \mathrm{m}^{2}\right)$ & & 190,4 & \\
\hline$\left(\lambda_{10, d r y}\right)$ Thermal conductivity in dry & $\mathrm{W} / \mathrm{mK}$ & & 0,631 & \\
\hline
\end{tabular}


Since the values in Table 7 represent values for dry environment conditions, during calculations it is necessary to change them into the design coefficient of thermal conductivity depending on actual humidity conditions and application of BlokOL.

\section{CONCLUSION}

The review of the application area of the bricks and roof tiles waste as partial substitute for natural aggregate in concrete identified the research area of this paper. The identification of the research area lead to the conclusion that there is a need for detailed research and proof of the possibility for using concrete with crushed bricks and roof tiles as aggregate in production of constructive elements - concrete blocks, as the result of such concrete application definition. After experimental tests on EM-BM42, MM-B10 and RM samples in hardened state at room temperature were conducted, their results showed that samples with crushed bricks and roof tiles as aggregate in relation to reference samples have on average $27 \%$ lower compressive strength, $16 \%$ lower flexural strength, 19\% lower hardened state density, 50\% lower modulus of elasticity, $20 \%$ lower ultrasonic pulse velocity. Since the main goal is to define the composition of concrete mixture with the highest possible percentage of crushed bricks and roof tiles as substitute for natural aggregate, with satisfactory mechanical and thermal properties, for production of floor blocks, the optimum mixture based on experiment was selected, with $50 \%$ fine particle and $75 \%$ course particle substitute of natural aggregate with crushed bricks and roof tiles. Mechanical resistance of BlokOL was tested on samples after their exposure to high temperatures. The test results indicate that BlokOL possesses a satisfactory mechanical resistance even after its exposure to high temperatures. After conducted experimental tests of BlokOL it was determined that BlokOL complies with the requirements prescribed by the norm HRN EN 15037-2:2009 and that it can be used as a sem i-resistive floor block of the precast floor construction - SR, mechanical resistance class - R2, volume tolerance class - T1, reaction to fire - A1, gross density in dry state $1995 \mathrm{~kg} / \mathrm{m}^{3}$. Also, it was determined that BlokOL possesses satisfactory mechanical properties even after it has been exposed to high temperatures.

\section{REFERENCES}

Cachim, P.B., Mechanical properties of brick aggregate concrete, Construction and Building Materials 23 (2009) 1292-1297

Debieb, F. and Kenai, S., The use of coarse and fine crushed bricks as aggregate in concrete. Construction and Building Materials 22 (2008) 886-893

Yang, J., Du, Q., Bao, Y., Concrete with recycled concrete aggregate and crushed clay bricks, Construction and Building Materials 25 (2011) 1935-1945

Tam, V. W. Y., Gao, X. F., Tam, C. M., Microstructural analysis of recycled aggregate concrete produced from two-stage mixing approach, Cement and Concrete Research 35 (2005) 1195- 1203

Kraus, I, Paradžiković, M., Miličević, I., 2012, Effects of infills made of concrete containing crushed bricks/tiles on seismic response of short columns. Elektronički časopis građevinskog fakulteta osijek egfos, no. 5: p. 43-51.

Miličević, I., 2014, Fire resistance of concrete with crushed bricks and roof tiles, Ph.D. Thesis, Faculty of Civil Engineering Osijek, University J.J. Strossmayer Osijek.

Miličević, I., Štirmer, N., Bjegović, D., 2014, Optimization of concrete mixtures made with crushed clay bricks and roof tiles. // Magazine of concrete research, DOI: 10.1680/macr.14.00175, Available online: 07 October 2014, ISSN: 0024-9831

Bjegović, D.; Serdar, M.; Stipanović Oslaković, I. 2010: Assessment of concrete properties in structures, Handbook of concrete durability, Kim, S.-H.; Ann, K.Y. (editor), Korea: Middleton Publishing Inc., pp. 131-179 